\title{
The Ontogenesis of Human Fetal Hormones
}

\author{
III. PROLACTIN
}

\author{
Michel L. Aubert, Melvin M. Grumbach, and Selna L. Kaplan \\ Department of Pediatrics, University of California at San Francisco, \\ San Francisco, California 94143
}

A B S T R A C T The synthesis and release of human prolactin (hPRL) in the human fetus was assessed by radioimmunoassay analysis of the content and concentration of hPRL in 82 pituitary glands and the concentration of serum hPRL in 47 fetuses of gestational age 68 days to term. Fetal hPRL exhibited parallelism with the reference standard (Lewis 203-1). hPRL was detected by 68 days of gestation ( $10 \mathrm{wk})$, the earliest fetal pituitary gland studied; 8 out of 33 pituitaries had a prolactin (PRL) content above $2.0 \mathrm{ng}$ between $10-15$ wk gestation. The mean content of PRL in the pituitary gland increased sharply from $14.8 \pm 4.6 \mathrm{ng}$ at $15-19 \mathrm{wk}$ to $405 \pm 142 \mathrm{ng}$ at $20-24 \mathrm{wk}$ and $542 \pm 204 \mathrm{ng}$ at $25-29$

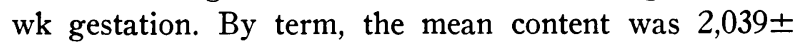
459 (range 493-3,689) and the mean concentration $15.9 \pm 2.4 \mathrm{ng} / \mathrm{mg}$ (range 7-20). There was a significant positive correlation $(P<0.001)$ between the hPRL and human growth hormone $(\mathrm{hGH})$ content of fetal pituitary glands; at term the $\mathrm{hPRL} / \mathrm{hGH}$ ratio was $1 / 290$. The concentration of serum hPRL between 12 and $24 \mathrm{wk}$ ranged from 2.9 to $67 \mathrm{ng} / \mathrm{ml}$, mean $19.5 \pm 2.5 \mathrm{ng} / \mathrm{ml}(n=$ 41 ) ; by 26 wk fetal serum hPRL increased sharply and attained levels of $300-500 \mathrm{ng} / \mathrm{ml}$ in late gestation. At delivery, the mean plasma concentration of hPRL was $167 \pm 14.2 \mathrm{ng} / \mathrm{ml}$ in 36 umbilical venous specimens and $111.8 \pm 12.3 \mathrm{ng} / \mathrm{ml}$ in the matched maternal venous specimens. No correlation between serum hPRL and the pituitary content or concentration of hPRL was demonstrable in 12 matched fetal specimens.

In five anencephalic infants, umbilical venous hPRL levels were between 65 and $283 \mathrm{ng} / \mathrm{ml}$. In two anencephalic infants, thyrotropin releasing factor (TRF) $(200 \mu \mathrm{g}$ IV) evoked a rise in serum hPRL in one patient from 43 to $156 \mathrm{ng} / \mathrm{ml}$ at $30 \mathrm{~min}$, and in the other from 65 to

Dr. Aubert is recipient of a grant from the Swiss National Fund for Scientific Research.

Received for publication 6 December 1974 and in revised form 5 March 1975.
$404 \mathrm{ng} / \mathrm{ml}$ at $120 \mathrm{~min}$. In both patients, plasma thyroidstimulating hormone (TSH) rose from undetectable base-line levels to peak levels of 97 and $380 \mu \mathrm{U} / \mathrm{ml}$, respectively. The pattern of change in serum hPRL in the human fetus contrasts sharply with that of serum $\mathrm{hGH}$, luteinizing hormone, or follicle-stimulating hormone.

These observations in the fetus and in anencephalic infants suggest that the striking elevation of serum PRL in the fetus is neither mediated by a putative PRL releasing factor or by $\mathrm{TRF}$, nor is a consequence of suppression or absence of PRL release inhibiting factor alone, as a functional hypothalamus is not required to attain the high PRL concentration at term. Several lines of evidence support the view that high plasma estrogen levels characteristic of gestation act directly on the fetal anterior hypophysis to stimulate PRL secretion or to sensitize the secretory mechanism of the lactotrope, increasing its responsiveness to other stimuli.

\section{INTRODUCTION}

Human pituitary prolactin (hPRL) ${ }^{1}$ only recently has been isolated and characterized $(1,2)$ and specific radioimmunoassays developed (3-6) even though many clinical, physiological, and histological observations had suggested the existence of a separate prolactin (PRL) in man (7-11).

Little is known about the ontogenesis of hPRL. Its concentration in the maternal circulation increases strikingly during pregnancy; similarly, high PRL levels are present in umbilical cord blood at term (12). PRL-like

${ }^{1}$ Abbreviations used in this paper: anti-oPRL, antiovine prolactin; GH, growth hormone; GRF, growth hormone releasing factor; hGH, human growth hormone; hPRL, human prolactin; PIF, prolactin release inhibiting factor; PRF, prolactin releasing factor; PRL, prolactin; RIA, radioimmunoassay; TRF, thyrotropin releasing factor; $\mathrm{TSH}$, thyroid-stimulating hormone. 


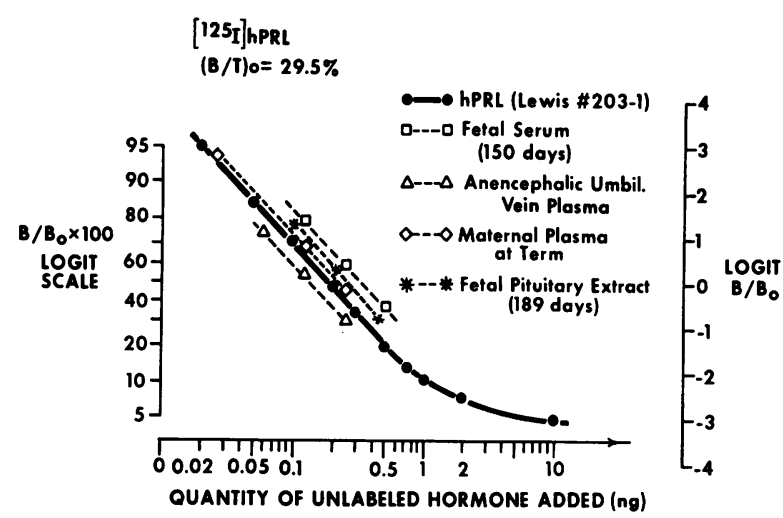

Figure 1 A typical standard curve for the heterologous radioimmunoassay system for hPRL. Anti-oPRL serum (R-246) was used at a final dilution of $1: 40,000$ and hPRL (Lewis-203-1) as tracer and standard.

biologic activity in the fetal pituitary gland of midgestation fetuses was reported by Levina (13); Pasteels, Brauman, and Brauman (14) detected by bioassay PRL activity in cultures of human fetal pituitary glands. In animals, PRL has been identified in the fetal pituitary gland of several species (15-17) and in the serum of late gestation sheep fetuses $(18,19)$.

Preliminary studies from this laboratory $(20,21)$ provided evidence for the synthesis and release of fetal pituitary PRL in man. The present communication describes in more detail changes in the content of PRL in fetal pituitaries, an abrupt change in serum PRL during gestation, the relationship of these observations to ongoing studies of the ontogenesis of other pituitary hormones (21-24, and footnote 2), and the maturation of hypothalamic control of pituitary function.

There are inherent limitations in measuring the hormone content of an endocrine gland and not its flux and in the interpretation of serum PRL concentrations without knowledge of its metabolic clearance rate in the fetus. In addition, other factors can affect the results including the accuracy of the assessment of fetal age, the random nature of the fetal specimens available, unrecognized artifacts related to the state of the fetuses studied, and the possible episodic or pulsatile secretion of PRL.

\section{METHODS}

Pituitary glands were obtained from 82 fetuses ( 27 by spontaneous and 55 by therapeutic abortions) and from four infants at postmortem examination. Gestational age was estimated either from crown-rump measurements or from calculations obtained by subtraction of 14 days from the

\footnotetext{
${ }^{2}$ Kaplan, S. L., and M. M. Grumbach. 1975. The ontogenesis of human fetal hormones. II. Luteinizing hormone (LH) and follicle stimulating hormone (FSH). Acta Endocrinol. In press.
}

onset of the mother's last menstrual period, or by both methods. The preparation of the extracts has been described (22). Specimens of blood were obtained from 47 aborted fetuses including 12 from which the pituitary glands were also obtained, 36 from normal deliveries (maternal and umbilical vein), and 5 from anencephalic infants. Plasma was obtained in all cases except for the fetus for which only serum was available.

The radioimmunoassay (RIA) of hPRL was performed by a double antibody method (6). Briefly, a heterologous RIA system was used which consisted of a rabbit antiovine PRL (anti-oPRL) and hPRL as tracer and standard. The anti-oPRL cross-reacts with hPRL completely and gives results which are comparable to the homologous assay systems. hPRL was iodinated by a modification of the chloramine-T method (25), and an aliquot of the [ $\left.{ }^{225} \mathrm{I}\right]-$ hPRL was repurified on a Sephadex G-100 column (0.9 $\times 55 \mathrm{~cm}$ ) before each assay (Pharmacia Fine Chemical Inc., Piscataway, N. J.). All hPRL values are expressed in terms of the purified Lewis 203-1 preparation. Human growth hormone (hGH) was determined by RIA (22) and the results expressed in terms of the Wilhelmi 840 preparation of hGH. RIA results were analyzed with an IBM-360 computer using a RIA data processing program prepared at the National Institutes of Health and kindly supplied to us by Dr. D. Rodbard. Statistical analysis of the data was performed according to Snedecor and Cochran (26) on a 9830-A Hewlett-Packard desk calculator (Hewlett-Packard Calculator Products Division, Loveland, Colo.).

The thyrotropin releasing factor (TRF) preparation was a gift of Dr. R. Guillemin, Salk Institute, La Jolla, California.

\section{RESULTS}

Specificity of the RIA. The specificity of the heterologous RIA for hPRL in this study is described elsewhere (6). The anti-oPRL does not cross-react with human chorionic somatomammotropin, human chorionic gonadotrophin, or hGH. The Research Standard A (no. 71-222) distributed by the National Institute for Biological Standards and Control, Hampstead, England (27) was found to be $30 \%$ as active as the Lewis $203-1$ preparation; the reference plasma (no. 71-167) had a mean concentration of $29.3 \pm 1.7 \mathrm{ng} / \mathrm{ml}$ in 16 assays.

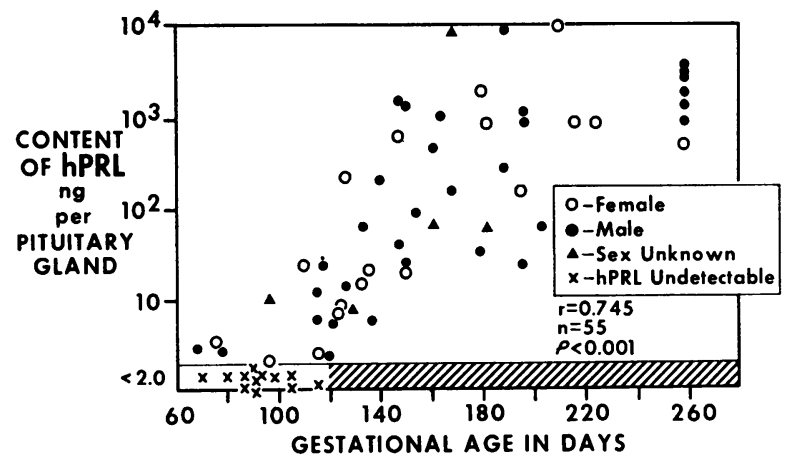

FIgURe 2 The content of hPRL in human fetal pituitary glands is plotted in nanograms on the ordinate (logarithmic scale) against gestational age on abscissa. 
TABLE I

PRL Content of Human Fetal and Newborn Pituitary Glands*

\begin{tabular}{|c|c|c|c|c|c|c|c|c|}
\hline \multirow{2}{*}{$\begin{array}{c}\text { wk } \\
\text { gestation }\end{array}$} & \multirow[b]{2}{*}{ Mean \pm SE } & \multirow[b]{2}{*}{$n$} & \multirow[b]{2}{*}{ Range } & \multicolumn{5}{|c|}{ Statistical analysis, $\ddagger$ wk of gestation } \\
\hline & & & & $15-19$ & $20-24$ & $25-29$ & $35-40$ & 1-2 mo \\
\hline $10-14 \S$ & $4.1 \pm 1.4$ & 5 & $2.1-9.7$ & 0.034 & $<0.001$ & $<0.001$ & $<0.001$ & $<0.001$ \\
\hline $15-19 \S$ & $14.8 \pm 4.6$ & 13 & $2.4-65.6$ & & $<0.001$ & $<0.001$ & $<0.001$ & $<0.001$ \\
\hline $20-24 \S$ & $405 \pm 142$ & 14 & $5.8-1,540$ & & & NS & 0.002 & 0.003 \\
\hline $25-29 \S$ & $542 \pm 204$ & 10 & $24-1,947$ & & & & 0.007 & 0.008 \\
\hline $30-34$ & 872 & 2 & $(856,887)$ & & & & & \\
\hline $35-40 \S$ & $2,039 \pm 459$ & 7 & $493-3,689$ & & & & & NS \\
\hline $1-2 \mathrm{mo}$ & $5,429 \pm 2,275$ & 4 & $833-9,855$ & & & & & \\
\hline
\end{tabular}

* ng Lewis 203-1 hPRL.

$\ddagger P$ values of individual unpaired $t$ test using logarithmic transforms.

§ One-way analysis of variance including five groups indicated: $F=14.180, P<0.001$ (with $\log$ transforms:

$F=25.511, P<0.001)$.

The limit of sensitivity of the RIA ranged between 0.02 $0.05 \mathrm{ng}$.

All maternal and fetal specimens in this study were examined for immunological identity with the hPRL reference preparation (Fig. 1). The displacement curves obtained with serial dilutions of fetal pituitary extracts, fetal serum, anencephalic umbilical venous plasma, and maternal plasma at term were parallel to the standard curve prepared with the Lewis 203-1 hPRL preparation. Using a mixed heterologous radioimmunoassay for hPRL as described by Jacobs, Mariz, and Daughaday (4) similar parallelism was found. The between-assay coefficient of variation was $4.7 \%$ (in 16 assays using reference plasma no. 71-167: B/Bo 50\%), the withinassay coefficient of variation, estimated by assaying the same reference plasma at least four times in duplicate in the same assay, was $4.3 \pm 1.4 \%$ ( $\pm \mathrm{SE}$ ) for six assays. hPRL did not displace $\left[{ }^{125} \mathrm{I}\right] \mathrm{hGH}$ tracer bound to anti-hGH in the RIA for hGH.

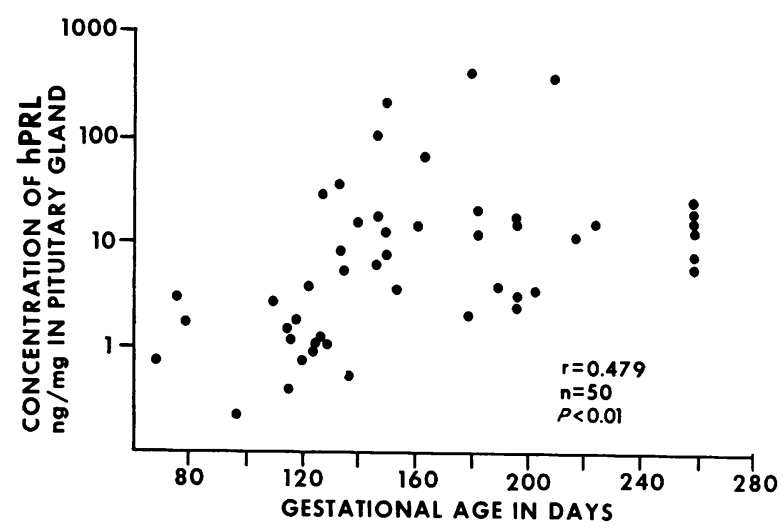

Figure 3 Comparison of the concentration (nanogram/ milligram) of hPRL in fetal pituitary glands with gestational age.
Pituitary PRL. Immunoreactive PRL was detected in the fetal pituitary gland as early as 68 days of gestation, the youngest pituitary gland assayed $(2.8 \mathrm{ng})$. However, between 68 and 115 days of gestation, only 8 of 33 fetal pituitary glands had PRL levels above 2.0 ng. After 115 days of gestation, all except two pituitary glands had detectable PRL. A marked increase was observed between 100-160 days of gestation for both pituitary content (Fig. 2) and concentration (Fig. 3), whereas for the last 100 days of gestation, the increase in PRL content was less striking and the values for concentration remained relatively constant. For both content and concentration, there was a significant positive correlation with gestational age, the correlation coefficient for content being higher. There was no rela-

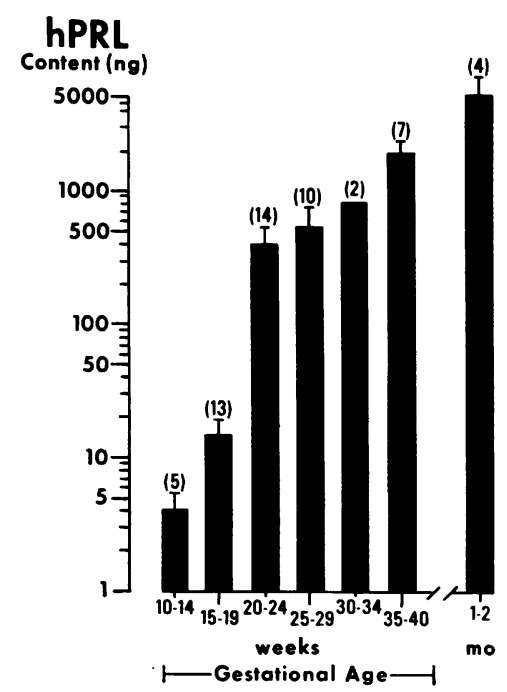

FIgUre 4 The content (Mean \pm SE) of hPRL in nanograms is plotted at 4-wk intervals during gestation and for postnatal ages 1-2 mo.

Ontogenesis of Human Fetal Hormones 


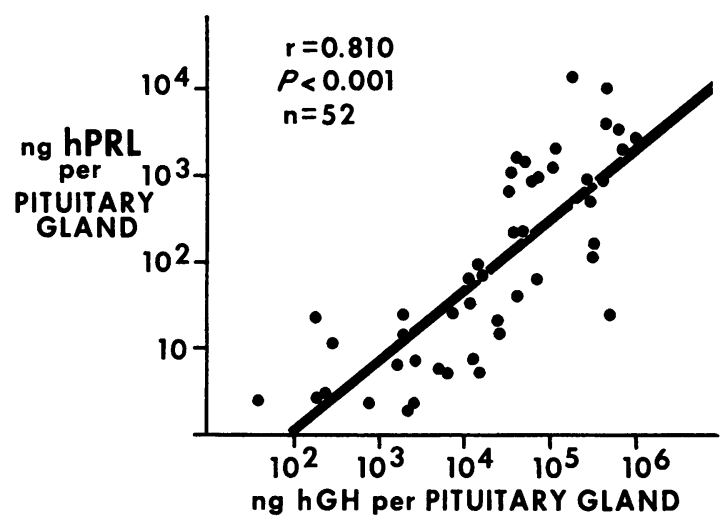

FIGURE 5 Correlation of the content of hPRL and hGH in the same fetal pituitary gland (note the difference in scale).

tion between the sex of the fetus and pituitary content or concentration of PRL.

The mean PRL content was compared at 5-wk intervals (Fig. 4). There was an uneven age distribution of the fetal pituitary glands studied with 39 of the $\mathbf{5 5}$ glands falling between 15 and 29 wk of gestation. A one-way analysis of variance of pituitary PRL content between groups at $10-14,15-19,20-24,25-29$, and 35-40 wk of gestation showed a highly significant $F$ ratio of 14.180 , $P<0.001$. This ratio rose to 25.511 when logarithmic transforms were used (Table I). The difference between the mean PRL content at 10-14 and 15-19 wk was of low statistical significance $(P=0.034)$ when analyzed by the unpaired $t$ test using logarithmic transforms, whereas the incremental change between the 15-19 and 20-24 wk and that between 25-29 and 35-40 wk groups was highly significant (Table I). The increase in PRL content between the 20-24 and 25-29 wk group was not significant. Four pituitary glands from 1-2-mo-old infants had a mean PRL content of 5,429 $\pm 2,275 \mathrm{ng}$ (833$9,855)$; although higher than in the late gestation group, the difference was not statistically significant. The changes in pituitary PRL concentration during gesta-

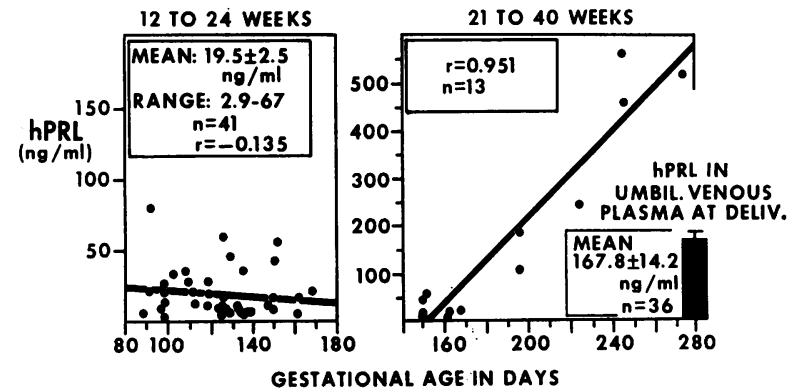

Figure 6 A comparison of the concentration of immunoreactive hPRL (nanograms/milliliter) in fetal serum with gestational age.

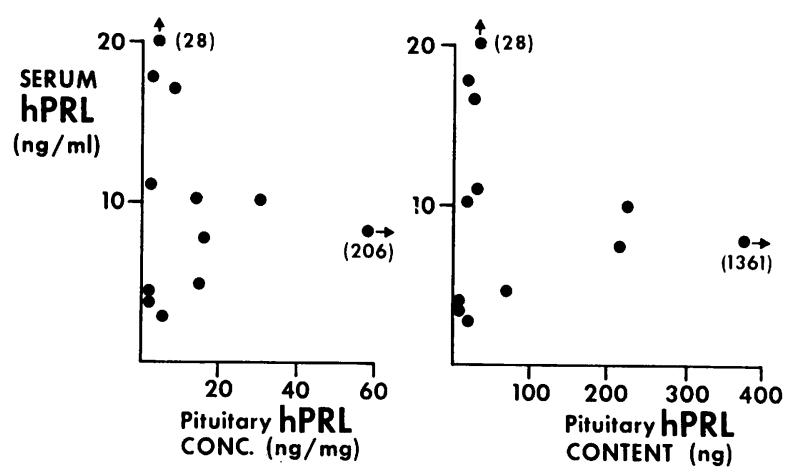

FIGURE 7 The concentration of serum hPRL (nanogram/ milliliter) on the ordinate is compared with the concentration (nanogram/milligram) (left panel) and with content (nanogram) (right panel) of pituitary hPRL in paired serum and pituitary samples obtained from 12 human fetuses.

tion were less striking than those for pituitary content. However, a significant positive correlation was observed between pituitary concentration and gestational age $(r=0.479, P<0.01)$ (Fig. 3$)$. The mean concentration in late gestation $(35-40 \mathrm{wk})$ was $15.9 \pm 2.4(\mathrm{SE})$ $(n=7) \mathrm{ng} / \mathrm{mg}$ PRL.

The PRL content of 52 fetal pituitary glands was compared with the growth hormone (GH) content previously reported (22). Fig. 5 indicates the highly significant positive correlation found when comparing the logarithmic values of the content of pituitary $\mathrm{GH}$ and PRL. Of note is the difference in the absolute amounts of fetal pituitary PRL and GH. From the slope of the regression line, the overall ratio of PRL to GH was $1 / 125$. In late gestation ( $35-40 \mathrm{wk})$, the PRL to $\mathrm{GH}$ ratio fell to $1 / 290$.

Serum PRL concentration in the fetus. PRL was present at a concentartion of $5.7 \mathrm{ng} / \mathrm{ml}$ in the youngest of 47 fetuses studied from 88 days to term. All fetuses 88 to 165 days gestation had detectable serum PRL; there was little change in the pattern of serum PRL concentration (Fig. 6). Beginning at about 180 days gestation there was a progressive rise in concentration of serum PRL to very high levels in the last few weeks of gestation. The concentrations in the three fetuses near term are higher $(458,520$, and $560 \mathrm{ng} / \mathrm{ml})$ than those in the umbilical venous plasma at term. In 12 fetuses 110-161 days gestation, from which matched sera and pituitary specimens were obtained, there was no correlation between the concentration of serum PRL and the pituitary content or concentration of PRL (Fig. 7).

Concentration of plasma PRL at term. The mean concentration was $167.8 \pm 14.2( \pm \mathrm{SE}) \mathrm{ng} / \mathrm{ml}$ in umbilical vein plasma (range 50-422), significantly higher $(P=0.004)$ than for maternal plasma, $111.8 \pm 12.3 \mathrm{ng} /$ 

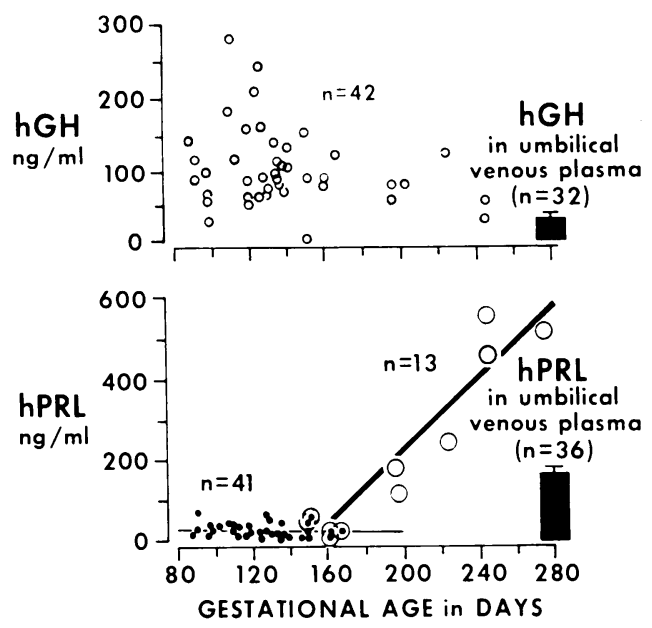

FIGURE 8 Comparison of the pattern of change in the concentration of serum hGH (top) and hPRL (bottom) during gestation.

$\mathrm{ml}$ (range 26-410). The PRL concentration of the 36 matched samples of maternal and fetal plasma correlated weakly but significantly with each other $(P<$ $0.05)$.

The pattern of change in fetal serum GH during gestation is in sharp contrast to that of serum PRL (Fig. 8); fetal serum $\mathrm{GH}$ reaches a peak concentration at midpregnancy and then decreases until term (22). There is a significant negative correlation between serum $\mathrm{GH}$ and gestational age $(P<0.001)$, whereas there is a positive correlation for serum PRL with fetal age from day 160 to term.

Studies in anencephalic infants. The concentration of plasma hPRL in five anencephalic infants on the 1st and 2 nd day of life (the absence of hypothalamic tissue was confirmed at postmortem in each case) was within the same range as for 36 normal newborns at delivery (Table II). In contrast, the plasma GH levels were

TABLE II

Serum $h P R L$ and $h G H$ in Five Anencephalic Infants

\begin{tabular}{ccc}
\hline Age & Serum hPRL* & Serum hGH \\
\hline days & $n g / m l$ & $n g / m l$ \\
1 & 100 & 1.0 \\
1 & 101 & 1.5 \\
1 & 148 & 1.4 \\
1 & 283 & 6.0 \\
2 & 65 &
\end{tabular}

Normal newborn infants

$167.8 \pm 14.2 \quad 35.5 \pm 4.6$

Umbilical venous plasma

range 50-422 range $6.0-93.0$

Mean \pm SE

$n=36$

$n=29$
TABLE III

Effect of TRF (200 $\mu \mathrm{g} I V)$ on Plasma PRL and TSH in Two Anencephalic Infants

\begin{tabular}{rrrrrr}
\hline & \multicolumn{2}{c}{ Patient 1 } & & \multicolumn{2}{c}{ Patient 2 } \\
\cline { 2 - 3 } Time & PRL* & TSH & & PRL* & TSH \\
\hline $\min$ & & $\mu U / m l$ & & $\mu U / m l$ \\
0 & 43 & $<0.5$ & & 65 & $<0.5$ \\
10 & 80 & 5.5 & & 134 & $<0.5$ \\
20 & 104 & 31 & & & \\
30 & 156 & 54 & & 187 & 340 \\
45 & 143 & 84 & & & \\
60 & 152 & 97 & & 242 & 380 \\
120 & 120 & 76 & & 404 & $>100$ \\
\hline
\end{tabular}

${ }^{*} \mathrm{ng} / \mathrm{ml}$ Lewis 203-1.

strikingly depressed (range $1-6 \mathrm{ng} / \mathrm{ml}$ ) when compared with the umbilical vein plasma hGH concentrations of 29 normal infants (Table II).

A TRF stimulation test performed in two anencephalic infants evoked a sharp rise in the concentration of plasma PRL (Table III). In contrast to the high basal value for plasma $\mathrm{PRL}$, plasma thyroid-stimulating hormon ( TSH) was less than $0.5 \mu \mathrm{U} / \mathrm{ml}$ in the zero time specimens; however, after TRF administration, there was a striking increase in plasma TSH.

\section{DISCUSSION}

The data presented herein indicate that the pituitary gland of the human fetus is able to synthesize, store, and secrete PRL early in gestation and are consistent with a progressive increase in secretion by the lactotropes during the last trimester of gestation. At term, the mean umbilical vein plasma concentration of PRL is higher than the mean maternal plasma level (Fig. 9).

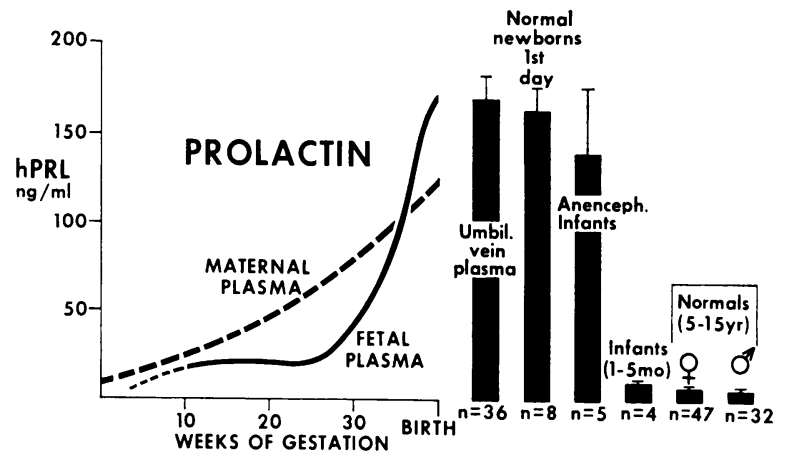

Figure 9 Comparison of the pattern of change of fetal and maternal plasma hPRL during gestation. On the right, plasma levels in normal and anencephalic newborns are compared with those of normal infants and adults (6). Levels for maternal plasma PRL during gestation are indicated as a composite curve using data from this laboratory and from reference 12 .

Ontogenesis of Human Fetal Hormones 
The immunochemical properties of fetal PRL are not different from those of adult or standard PRL in the test systems used. There was strict parallelism when the fetal hormone was examined in serial dilutions using two different antibodies in two different radioimmunoassay systems. No heterogeneity of immunoreactive PRL, such as high molecular weight forms ("big PRL"), was detected in the umbilical plasma of one fetus after gel filtration on Sephadex G-100. ${ }^{3}$ Neither hGH nor hCS cross-reacted in the PRL radioimmunoassay.

The onset of PRL synthesis and storage in the fetal pituitary gland occurs early in gestation. Fetal PRL was detected in the pituitary gland of the youngest fetus studied (68 days of gestation) and in the following 40day period of gestation 8 of 33 pituitary glands studied had a PRL content higher than $2.0 \mathrm{ng}$. From 115 days gestation all but two pituitary glands had detectable PRL and both the pituitary content and concentration increased significantly with gestational age.

These observations confirm earlier studies of Levina (13), who reported an increase in PRL biological activity of fetal pituitary glands between 18-40 wk of gestation. Further, Pasteels, and coworkers (14) detected PRL biological activity in cultures of human fetal pituitary glands from fetuses of 5 mo gestation. Recently, Siler-Khodr, Morgenstern, and Greenwood (28) demonstrated immunoreactive PRL activity in the media of cultures of human fetal pituitary glands from $5 \mathrm{wk}$ gestation until term. Their data suggest that the primordium of the fetal pituitary gland contains cells with the capacity to synthesize PRL. Using immunofluorescence techniques, Pasteels, Gausset, Danguy, and Ectors (29) detected lactotropes in the pituitary gland of a 4-mo-old fetus.

The pattern of change in the concentration of fetal serum PRL during gestation correlates overall with the increase in pituitary PRL content. However, no incremental changes in the concentration of serum PRL is observed between 88 and 165 days gestation, in contrast to the steadily increasing pituitary PRL content. The striking increase of serum PRL from 165 days to term is associated with a further increase of pituitary PRL content. The increase in fetal and maternal concentrations of serum hPRL show a similar general trend during gestation; however, serum hPRL appears to rise later and attains a higher mean level in the fetal than in the maternal circulation. There was a weak but significant correlation between fetal and maternal hPRL levels at term. Despite this similarity in the pattern of change, it is likely that the hPRL secretion in the mother and the fetus are independent and that there

\footnotetext{
${ }^{3}$ Garnier, P. E., M. L. Aubert, S. L. Kaplan, and M. M. Grumbach. Unpublished data.
}

is no or limited placental tranfer of hPRL, but definitive data in man are lacking. There is evidence of the impermeability of the sheep placenta for PRL (30). Recently, the transfer of labeled $\left[{ }^{125} \mathrm{I}\right] \mathrm{hPRL}$ from the maternal to the fetal circulation in the rhesus monkey has been shown to be less than $1 \%$ (31). Indirect evidence of the lack of or limited placental transfer of hPRL in humans is the persistence of high hPRL levels in the newborn infant for several weeks $(6,32)$.

The serum PRL levels in the five anencephalic infants and in three others reported by Hayek, Driscoll, and Warshaw (33) were comparable to those of normal newborn infants. This finding indicates that $(a)$ a functional hypothalamus is not required to attain the high PRL levels at term, and $(b)$ pituitary lactotropes, independent of hypothalamic control, apparently are responsive to gestational factors. The high PRL levels in the anencephalic infants, compared with those of normal children and adults, represent important evidence against the possibility that TRF or a putative human $\mathrm{PRL}$ releasing factor ( $\mathrm{PRF}$ ) are responsible for the late gestational PRL rise in the fetal circulation.

PRL secretion is known to be regulated by a tonic inhibitory mechanism of hypothalamic origin (34). Removing the pituitary gland from hypothalamic control results in an increase in PRL secretion, as seen with pituitary gland autograft (35) or after pituitary stalk section in man (36). Whether PRL release inhibiting factor (PIF) is a peptide, similar to the already characterized hypothalamic factors, or dopamine, a neurotransmitter, is not yet known (37-41). Although postulated in certain animals species (42), the existence of a human PRF is very uncertain. The stimulation of PRL by TRF, first observed in vitro (43), is now well documented in man (44-46); however, there is no evidence that TRF is the hypothetical PRF.

What are the mechanisms involved in the sharp rise of plasma PRL in the maternal and fetal circulations toward the end of gestation? Several aspects should be considered: $(a)$ the modulation of the hypothalamic control of PRL in pregnant women, $(b)$ the maturation of this control in the fetus, and $(c)$ the influence of the gestational hormones on the hypothalamus and/or the pituitary gland of the fetus and the pregnant woman.

The progressive increase of plasma PRL concentration in the pregnant women could be due, at least in part, to the suppression of PIF secretion or blockade of its effect on the pituitary gland with concomitant hyperplasia of the pituitary lactotropes (47). However, there are several lines of evidence which indicate that the high plasma estrogens characteristic of gestation stimulate the pituitary lactotropes directly and can elicit a greater degree of stimulation of the pituitary gland (6, $48,49)$ than usually occurs with PIF deficiency or phar- 
macological agents. Similary, an active role of estrogens can be postulated in the fetus for the striking rise of serum PRL after 180 days of gestation. Indeed, estrogens, mainly of placental origin, increase sharply in the maternal and fetal circulation during gestation. Shutt, Smith, and Shearman (50) reported striking increases of unconjugated $17 \beta$-estradiol as well as estrone and estriol between 15-20 wk gestation and term in both the fetal and maternal plasma.

The influence of estrogens on plasma PRL is well documented (4, 6, 32, 48, 49). Frantz, Kleinberg, and Noel (48) have demonstrated that estrogen treatment of male subjects increases their plasma PRL levels significantly. Yen, Ehara, and Siler (51) found that within 3 wk of treatment with estrogen, hypogonadal women increased their concentration of plasma PRL up to $400 \%$ of basal levels. Further, estrogens are known to stimulate PRL secretion by the rat or rabbit pituitary gland in vitro $(52,53)$ and in vivo $(54,55)$. Additional support is provided by the observation that during pregnancy in the rhesus monkey, in contrast to man, there is only a moderate rise in maternal estrogen levels (56) and only a modest and variable increase in plasma PRL ${ }^{4}$ (57). Similarly, serum PRL increases only at the end of gestation in the ewe (58) and lamb fetus $(18,19)$. This late rise in PRL values correlates with the increase of circulating estrogens which occurs closely related to term in the fetal and maternal circulation in sheep (59).

Pregnancies with anencephalic fetuses are characterized by a striking reduction in the excretion of estriol in the maternal urine owing mainly to the diminished secretion by the fetal adrenals of $16 \alpha$-OH-dehydroepiandrosterone sulfate, the principal precursor of estriol in pregnancy $(60,61)$. However, estradiol and estrone in the fetal circulation originate mainly from precursors secreted by the maternal adrenal cortex $(60,61)$, therefore, the circulating levels of these two steroids in the fetus should not be greatly affected by anencephaly. This was recently demonstrated in one anencephalic infant in whom the high plasma concentrations of unconjugated $17 \beta$-estradiol and estrone in umbilical cord blood were in the normal range (62). In two anencephalic infants observed in this study, the augmented PRL response after TRF stimulation clearly demonstrates a large dynamic reserve of pituitary PRL in the anencephalic newborn and supports the notion that factors, which do not act via the hypothalamus, mediate this increased secretory capacity.

A comparison of the pattern of change in the serum concentration of the different pituitary hormones in the fetus and the anencephalic infant provides further sup-

\footnotetext{
${ }^{4}$ Novy, M. J., M. L. Aubert, M. M. Grumbach, and S. L.
} Kaplan. Unpublished data.
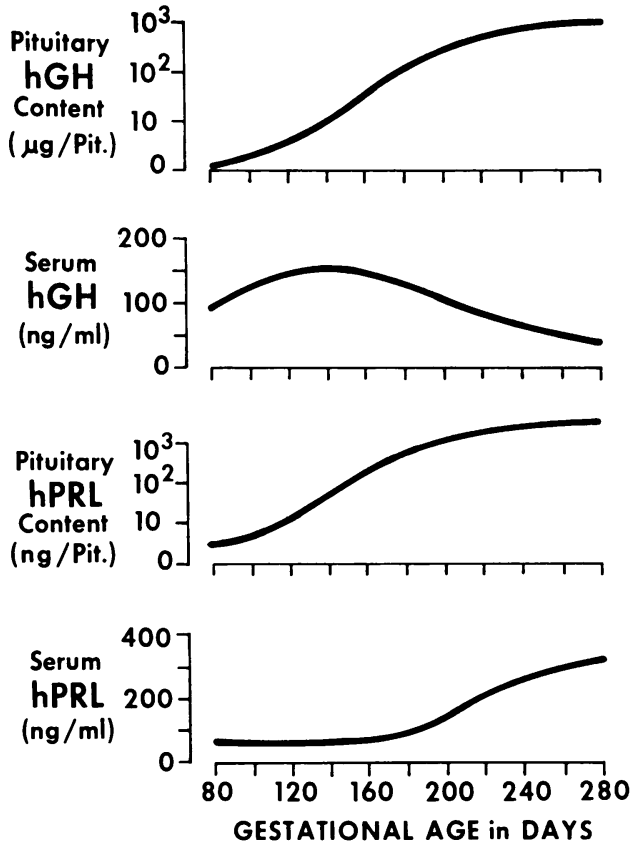

FIGURE 10 Schematic diagram of the pattern of change in pituitary and serum hPRL and hGH during gestation. Note that the content of pituitary hGH is expressed as $\mu \mathrm{g} / \mathrm{Pit}$. and hPRL content as ng/Pit.

port for the overall inhibitory nature of the hypothalamic control of PRL secretion in contrast to the stimulatory nature of control for the other pituitary hormones (21-24). In the case of hGH, although a $\mathrm{GH}$ release inhibiting factor or somatostatin has been described (63), the very low GH plasma levels usually found in anencephalic infants suggest that $\mathrm{GH}$ secretion in the fetus is primarily under the influence of a growth hormone releasing factor (GRF). Fig. 10 compares the pattern of change of pituitary content and serum concentration of PRL and hGH throughout gestation. We have postulated that the generally high serum levels of hGH observed in the fetus at midgestation are attributable to relatively unrestrained secretion of GRF (or lack of GIF), and that toward term the concentration of $\mathrm{hGH}$ in fetal serum decreases in response to maturation of inhibitory regulatory mechanisms $(21,22)$.

Phylogenetic studies from amphibia to mammals on the action of PRL indicate that it is the most versatile of all hormones (64). In man, PRL appears to promote the growth and secretory capacity of the maternal mammary gland in concert with other hormones during pregnancy. However, the role of PRL in the development of the human fetus is unknown. Neither hPRL nor hGH appear to be critical rate-limiting factors in the growth of the human fetus since apituitary fetuses are of normal or near-normal size at birth $(21,65,66)$. On the other hand, PRL in lower organisms exerts important metabolic effects including those on growth, water, and 
electrolyte metabolism, and on steroid target tissues. Buckman and Peake (67) have reported that PRL secretion in man is affected by changes in serum osmolarity. It may be that PRL has an influence on water and electrolyte metabolism in the human fetus, but there are no data on this possible action. Further studies may uncover previously unsuspected actions of PRL in the primate fetus. For example, the rise in serum PRL may be one factor in the fall in serum testosterone concentration in the male during the second half of gestation (68).

\section{ACKNOWLEDGMENTS}

We wish to acknowledge the valuable assistance of Dr. Thomas Shepard, and of Doctors Cynthia Barrett, Delbert Fisher, Mitchell Golbus, Abraham Rudolph, and Lotte Strauss in the collection of pituitaries and blood specimens from fetuses. Gail Doherty provided expert technical assistance. We thank the National Pituitary Agency for the purified hGH and Dr. U. J. Lewis and Dr. H. G. Friesen for the purified hPRL preparations. Dr. R. Guillemin generously provided the synthetic TRF.

This work was supported in part by grants from the National Institutes of Child Health and Human Development and the National Institute of Arthritis, Metabolism, and Digestive Diseases, National Institutes of Health, and U. S. Public Health Service.

\section{REFERENCES}

1. Lewis, U. J., R. N. P. Singh, and B. K. Seavey. 1971. Human prolactin: isolation and some properties. Biochem. Biophys. Res. Commun. 44: 1169-1176.

2. Hwang, P., H. Guyda, and H. Friesen. 1972. Purification of human prolactin. J. Biol. Chem. 247: 1955-1958.

3. Hwang, P., H. Guyda, and H. Friesen. 1971. A radioimmunoassay for human prolactin. Proc. Natl. Acad. Sci. U. S. A. 68: 1902-1906.

4. Jacobs, L. S., I. K. Mariz, and W. H. Daughaday. 1972. A mixed heterologous radioimmunoassay for human prolactin. J. Clin. Endocrinol. Metab. 34: 484-490.

5. Sinha, Y. N., F. W. Selby, U. J. Lewis, and W. P. VanderLaan. 1973. A homologous radioimmunoassay for human prolactin. J. Clin. Endocrinol. Metab. 36: 509516.

6. Aubert, M. L., M. M. Grumbach, and S. L. Kaplan. 1974. Heterologous radioimmunoassay for human prolactin (hPRL): values in normal subjects, puberty, pregnancy, and in pituitary disorders. Acta Endocrinol. $77: 460-476$.

7. Pasteels, J. L. 1967. Hormone de croissance et prolactine dans l'hypophyse humaine. Ann. Endocrinol. 28: $117-126$.

8. Herbert, D. C., and T. Hayashida. 1970. Prolactin localization in the primate pituitary by immunofluorescence. Science (Wash. D. C.). 169: 378-379.

9. Frantz, A. G., and D. L. Kleinberg. 1970. Prolactin: evidence that it is separate from growth hormone in human blood. Science (Wash. D. C.). 170: 745-747.

10. Friesen, H., H. Guyda, and J. Hardy. 1970. Biosynthesis of human growth hormone and prolactin. J. Clin. Endocrinol. Metab. 31: 611-624.

11. Lewis, U. J., R. N. P. Singh, Y. N. Sinha, and W. P. VanderLaan. 1971. Electrophoretic evidence for human prolactin. J. Clin. Endocrinol. Metab. 33: 153-156.
12. Tyson, J. E., P. Hwang, H. Guyda, and H. G. Friesen. 1972. Studies of prolactin secretion in human pregnancy. Am. J. Obstet. Gynecol. 113: 14-20.

13. Levina, S. E. 1968. Endocrine features in development of human hypothalamus, hypophysis, and placenta. Gen. Comp. Endocrinol. $11:$ 151-159.

14. Pasteels, J. L., H. Brauman, and J. Brauman. 1963. Etude comparée de la sécrétion d'hormone somatotrope par l'hypophyse humaine in vitro et de son activité lactogénique. C.R. Acad. Sc. (Paris). 256: 2031-2033.

15. Stokes, H., and J. M. Boda. 1968. Immunofluorescent localization of growth hormone and prolactin in the adenohypophysis of fetal sheep. Endocrinology. 83: 1362-1366.

16. Kohmoto, K., and H. A. Bern. 1971. Occurrence and secretion of prolactin in fetal mouse pituitaries. Proc. Soc. Exp. Biol. Med. 137: 807-809.

17. Oxender, W. D., E. M. Convey, and H. D. Hafs. 1972. Bovine fetal pituitary concentration in vitro synthesis of prolactin, GH, and LH. Proc. Soc. Exp. Biol. Med. 139: 1017-1021.

18. Moger, W. H., and I. I. Geschwind. 1971. Plasma prolactin levels in fetal sheep. Experientia (Basel). 27: 1479-1480.

19. Alexander, D. P., H. G. Britten, H. L. Buttle, and D. A. Nixon. 1972. Prolactin in sheep foetus. Res. Vet. Sci. 13: $188-189$.

20. Aubert, M. L., M. M. Grumbach, and S. L. Kaplan. 1973. Ontogenesis of prolactin (hPRL) in the serum and pituitary gland of human fetus and in anencephaly. Endocrinology. 92 : A49.

21. Grumbach, M. M., and S. L. Kaplan. 1973. Ontogenesis of growth hormone, insulin, prolactin, and gonadotropin secretion in the human foetus. Foetal and Neonatal Physiology, Proceedings of Sir Joseph Barcroft Centenary Symposium. Cambridge University Press, Cambridge. $462-487$.

22. Kaplan, S. L., M. M. Grumbach, and T. H. Shepard. 1972. The ontogenesis of human fetal hormones. I. Growth hormone and insulin. J. Clin. Invest. 51:30803093.

23. Fisher, D. A., C. J. Hobel, R. Garza, and C. A. Pierce. 1970. Thyroid function in the preterm fetus. Pediatrics. 46: 208-216.

24. Winters, A. J., C. Oliver, C. Colston, P. C. McDonald, and J. C. Porter. 1974. Plasma ACTH levels in the human fetus and neonate as related to age and parturition. J. Clin. Endocrinol. Metal. 39: 269-273.

25. Greenwood, F. C., W. M. Hunter, and J. S. Glover. 1963. The preparation of ${ }^{131} \mathrm{I}$-labeled human growth hormone of high specific radioactivity. Biochem. J. 89: 114 123.

26. Snedecor, G. W., and W. G. Cochran. 1967. Statistical Methods. Iowa State University Press, Ames, Iowa.

27. Cotes, P. M. 1973. Research standard A for human prolactin (in ampoules coded 71/222). Excerpta Med. Int. Congr. Ser. 308: 97.

28. Siler-Khodr, T. M., L. L. Morgenstern, and F. C. Greenwood. 1974. Hormone synthesis and release from human fetal adenohypophysis in vitro. J. Clin. Endocrinol. Metab. 39: 891-905.

29. Pasteels, J. L., P. Gausset, A. Danguy, and F. Ectors. 1972. Immunofluorescent studies on prolactin and the pituitary. In 4th Tenovus Workshop, Prolactin and Carcinogenesis. A. R. Boyns and K. Griffiths, editors. Alpha Omega Alpha Publishing, Cardiff, Wales. 128136. 
30. Alexander, D. P., H. G. Britton, H. L. Buttle, and D. A. Nixon. 1973. Impermeability of the sheep placenta towards endogenous prolactin. Res. Vet. Sci. 14: 271-272.

31. Josimovich, J. B., G. Weiss, and D. L. Hutchinson. 1974. Sources and disposition of pituitary prolactin in maternal circulation, amniotic fluid, fetus and placenta in the pregnant rhesus monkey. Endocrinology. 94: 1364-1371.

32. Guyda, H. J., and H. G. Friesen. 1973. Serum prolactin levels in humans from birth to adult life. Pediatr. Res. 7: $534-540$

33. Hayek, A., S. G. Driscoll, and J. B. Warshaw. 1973. Endocrine studies in anencephaly. J. Clin. Invest. 52: 1636-1641.

34. Meites, J., K. H. Lu, W. Wuttke, C. W. Welsch, H. Nagasawa, and S. K. Quadri. 1972. Recent studies on functions and control of prolactin secretion in rats. Recent Prog. Horm. Res. 28: 471-526.

35. Chen, C. L., Y. Amenomori, K. H. Lu, J. L. Voogt, and J. Meites. 1970. Serum prolactin levels in rats with pituitary transplants or hypothalamic lesions. Neuroendocrinology. $6: 220-227$.

36. Turkington, R. W., L. E. Underwood, and J. J. Van Wyk. 1971. Elevated serum prolactin levels after pituitary-stalk section in man. N. Engl. J. Med. 285: 707710 .

37. Blackwell, R. E., and R. Guillemin. 1973. Hypothalamic control of adenohypophysial secretions. Ann. Rev. Physiol. 35: 357-390.

38. MacLeod, R. M., and J. E. Lehmeyer. 1974. Studies on the mechanism of the dopamine-mediated inhibition of prolactin secretion. Endocrinology. 94: 1077-1085.

39. Dibbet, J. A., M. J. Boudreau, J. F. Bruni, and J. Meites. 1974. Possible role of dopamine in modifying prolactin (PRL) response to TRH. Endocrinology. 94: A186.

40. Takahara, J., A. Arimura, and A. V. Schally. 1974. Suppression of prolactin release by a purified porcine PIF preparation and catecholamines infused into a rat hypophysial portal vessel. Endocrinology. 95: 462-465.

41. Ojeda, S. R., P. G. Harms, and S. M. McCann. 1974. Effect of blockade of dopaminergic receptors on prolactin and $\mathrm{LH}$ release: median eminence and pituitary sites of action. Endocrinology. 94: 1650-1657.

42. Nicoll, C. S., R. P. Fiorindo, C. T. McKennee, and J. A. Parson. 1970. Assay of hypothalamic factors which regulate prolactin secretion. In Hypophysiotropic Hormones of the Hypothalamus. J. Meites, editor. Williams \& Wilkins, Baltimore. 115-150.

43. Tashjian, A. H., Jr., N. J. Barowsky, and D. K. Jensen. 1971. Thyrotropin releasing hormone: direct evidence for stimulation of prolactin production by pituitary cells in culture. Biochem. Biophys. Res. Commun. 43: 516523.

44. Bowers, C. Y., H. G. Friesen, P. Hwang, H. J. Guyda, and K. Folkers. 1971. Prolactin and thyrotropin release in man by synthetic pyroglutamyl-histidyl-prolinamine. Biochem. Biophys. Res. Commun. 45: 1033-1041.

45. Foley, T. P., Jr., L. S. Jacobs, W. Hoffman, W. H. Daughaday, and R. M. Blizzard. 1972. Human prolactin and thyrotropin concentrations in the serums of normal and hypopituitary children before and after the administration of synthetic thyrotropin-releasing hormone. J. Clin. Invest. 51: 2143-2150.

46. Kaplan, S. L., M. M. Grumbach, H. G. Friesen, and B. H. Costom. 1972. Thyrotropin-releasing factor
(TRF) effect on secretion of human pituitary prolactin and thyrotropin in children and in idiopathic hypopituitary dwarfism; further evidence for hypophysiotropic hormone deficiencies. J. Clin. Endocrinol. Metab. 35: 825-830.

47. Goluboff, L. G., and C. Erzin. 1969. Effect of pregnancy on the somatotroph and the prolactin cell on the human adenohypophysis. J. Clin. Endocrinol. Metab. 29: $1533-1538$

48. Frantz, A. G., D. L. Kleinberg, and G. L. Noel. 1972. Studies on prolactin in man. Recent Prog. Horm. Res. 28: $527-590$.

49. Tyson, J. E., and H. G. Friesen. 1973. Factors influencing the secretion of human prolactin and growth hormone in menstrual and gestational women. Am. J. Obstet. Gynecol. 116: 377-387.

50. Shutt, D. A., I. D. Smith, and R. P. Shearman. 1974. Oestrone, oestradiol-17 $\beta$, and oestriol levels in human foetal plasma during gestation and at term. J. Endocrinol. 60: 333-341.

51. Yen, S. S. C., Y. Ehara, and T. M. Siler. 1974. Augmentation of prolactin secretion by estrogen in hypogonadal women. J. Clin. Invest. 53: 652-655.

52. Ben-David, M., S. Dikstein, and F. G. Sulman. 1964. Effect of different steroids on prolactin secretion in pituitary-hypothalamus organ co-culture. Proc. Soc. Exp. Biol. Med. 117: 511-513.

53. Nicoll, C. S., and J. Meites. 1964. Prolactin secretion in vitro: effects of gonadal and adrenal cortical steroids. Proc. Soc. Exp. Biol. Med. 117: 579-583.

54. Kanematsu, S., and C. H. Sawyer. 1963. Effect of intrahypothalamic and intrahypophysial estrogen implants on pituitary prolactin and lactation in the rabbit. Endocrinology. 72: 243-252.

55. Ramirez, V. D., and S. M. McCann. 1964. Induction of prolactin secretion by implants of estrogen into the hypothalamo-hypophysial region of female rats. Endocrinology. 75 : 206-214.

56. Challis, J. R. G., I. J. Davies, K. Benirschke, A. G. Hendricks, and K. J. Ryan. 1974. The concentrations of progesterone, estrone, and estradiol-17 $\beta$ in the peripheral plasma of the rhesus monkey during the final third of gestation, and after the induction of abortion with $\mathrm{PGF}_{2 \alpha}$. Endocrinology. 95: 547-553.

57. Friesen, H., P. Hwang, H. Guyda, G. Tolis, J. Tyson and R. Myers. 1972. A radioimmunoassay for human prolactin: physiological, pathological, and pharmacological factors which affect the secretion of prolactin. In 4th Tenovus Workshop: Prolactin and Carcinogenesis. A. R. Boyns and K. Griffiths, editors. Alpha Omega Alpha Publishing, Cardiff, Wales. 64-80.

58. Davis, S. L., L. E. Reichert, Jr., and G. D. Niswender. 1971. Serum levels of prolactin in sheep as measured by radioimmunoassay. Biol. Reprod. 4: 145-153.

59. Alexander, D. P., H. G. Britton, C. S. Corker, F. Naftolin, and D. A. Nixon. 1973. Plasma luteinizing hormone and oestrogen in foetal and maternal sheep. $J$. Endocrinol. 56: 331-332.

60. MacDonald, P. C., and P. K. Siiteri. 1965. Origin of estrogen in woman pregnant with an anencephalic fetus. J. Clin. Invest. 44 : 465-474.

61. Siiteri, P. K., and P. C. MacDonald. 1966. Placental estrogen biosynthesis during human pregnancy. J. Clin. Endocrinol. 26: 751-761.

62. Kenny, F. M., K. Angsusingha, D. Stinson, and J. Hotchkiss. 1973. Unconjugated estrogens in the perinatal period. Pediatr. Res. 7 : 826-831.

Ontogenesis of Human Fetal Hormones 
63. Brazeau, P., W. Vale, R. Burgus, N. Ling, M. Butcher, J. Rivier, and R. Guillemin. 1973. Hypothalamic polypeptide that inhibits the secretion of immunoreactive pituitary growth hormone. Science (Wash. D. C.). 179: 77-79.

64. Bern, H. A., and C. S. Nicoll. 1968. The comparative endocrinology of prolactin. Recent Prog. Horm. Res. $24: 681-683$.

65. Brewer, D. B. 1957. Congenital absence of the pituitary gland and its consequences. J. Pathol. Bacteriol. 73: $59-67$.
66. Reid, J. D. 1960. Congenital absence of the pituitary gland. J. Pediatr. 56 : 658-664.

67. Buckman, M. T., and G. T. Peake. 1973. Osmolar control of prolactin secretion in man. Science (Wash. D. C.). 181: 755-757.

68. Grumbach, M. M., and S. L. Kaplan. 1975. Human fetal pituitary hormones and the maturation of central nervous system regulation of anterior pituitary function. In Modern Perinatal Medicine. L. Gluck, editor. Year Book Medical Publishers, Chicago. In press. 